\title{
Relationship between toll-like receptor 8 gene polymorphisms and pediatric pulmonary tuberculosis
}

\author{
Nazan Dalgic ${ }^{\mathrm{a}, *}$, Deniz Tekin ${ }^{\mathrm{b}}$, Zeliha Kayaalti ${ }^{\mathrm{b}}$, Erkan Cakirc, Tulin Soylemezoglu ${ }^{\mathrm{b}}$ and \\ Mesut Sancar ${ }^{\mathrm{d}}$ \\ a Sisli Etfal Training and Research Hospital, Division of Pediatric Infectious Diseases, Istanbul, Turkey \\ ${ }^{\mathrm{b}}$ Ankara University, Institute of Forensic Medicine, Ankara, Turkey \\ ${ }^{\mathrm{c}}$ Sureyyapasa Chest Diseases and Thoracic Surgery Teaching Hospital, Division of Pediatric Pulmonology, \\ Istanbul, Turkey \\ ${ }^{\mathrm{d}}$ Marmara University, Faculty of Pharmacy, Division of Clinical Pharmacy, Istanbul, Turkey
}

\begin{abstract}
Objectives: Genetic variants in Toll-like receptors (TLRs) are considered a potential indicator for host susceptibility to and outcome of several infectious diseases including tuberculosis. The aim of this study was to determine whether $-129 \mathrm{C} / \mathrm{G}$ and Met1Val polymorphisms of TLR8 were associated with pediatric pulmonary tuberculosis in Turkish population.

Methods: The $-129 \mathrm{C} / \mathrm{G}$ and Met1Val polymorphisms were studied in 124 children with pulmonary tuberculosis compared to 150 age-matched healthy control subjects.

Results: We did not identify any statistically significant differences between the patients with TB and control groups with regard to the frequency of genotypes $\mathrm{GG}$ or $\mathrm{G} /(-), \mathrm{CG}$, and $\mathrm{CC}$ or $\mathrm{C} /(-)$; and alleles $\mathrm{G}$ and $\mathrm{C}$ at $\mathrm{rs} 3764879(p>0.05)$. We found a strong association with genotype $\mathrm{A} /(-)$ at rs 3764880 with susceptibility to pulmonary TB in males (OR 2.87, $95 \%$ CI $1.38-5.98$, $p=0.007)$.

Conclusions: Our results provide evidence, for the first time, of a role for the TLR8 gene in susceptibility to pulmonary TB in male children. Additional research to verify our results are necessary. Tuberculosis in children presents particularly difficult challenges, but research priorities and advances in pediatric tuberculosis could provide wider insights and opportunities for tuberculosis control.
\end{abstract}

Keywords: Children, pulmonary tuberculosis, single nucleotide polymorphism, Toll-like receptor 8

\section{Introduction}

One third of the world population is infected with Mycobacterium tuberculosis (MTB), the bacterium that causes tuberculosis (TB); however, only $5-10 \%$ of those infected will develop active disease [1]. The immunological mechanisms that distinguish the majority of individuals who successfully contain these organisms from the minority who develop progressive mycobacterial disease are largely unknown. Innate im-

*Corresponding author: Nazan Dalgic, Halkali Cad. 45/3, Yesilkoy, 34149, Istanbul, Turkey. Tel.: +90 505580 3297; Fax: +90 212234 1121; E-mail: nazandalgic@ttmail.com. mune responses to pathogens are mainly orchestrated by monocytes/macrophages, granulocytes, and dendritic cells, which act as a first line of defense against invading microorganisms [2]. Discrimination of nonself from self is achieved by numerous host proteins equipped with the ability to recognize structures, or molecular patterns, present on foreign organisms [3]. One major family of proteins, the toll-like receptors (TLRs), play an important part in the innate immune recognition of invading microorganisms, initiating sufficient immune responses. Growing amounts of data suggest that the ability of certain individuals to respond properly to TLR ligands may be impaired by single nucleotide polymorphisms (SNPs) within TLR genes, 
resulting in an altered susceptibility to, or course of, infectious or inflammatory disease [4].

TLRs are primary transmembrane proteins of immune cells that stimulation of TLRs causes complex changes in the cellular microenvironment, including the release of a variety of cytokines and the induction of potent inflammatory and adaptive immune responses [5]. To date, 15 human TLR genes have been identified [6]. The most recently described TLRs to be implicated in responding to viral stimulation are TLR7 and TLR8, which share a high degree of structural similarity. They are located on the Xp22.2 chromosome at the membranes of the endosomal compartment and recognize viral single-stranded RNA (ssRNA) [7,8]. Literature reveals only one study on TB related to SNPs in the TLR8, which was conducted by Davila et al. [9]. The authors were the first to report that SNPs in the TLR8 gene on chromosome $\mathrm{X}$ showed evidence of association with TB in adult patients. The results suggest that it may play a significant role in TB infection susceptibility and disease activity, and thus should be the focus of concerted studies in human systems.

Pediatric and adult TB differ markedly in epidemiological features (two distinct peaks of incidence), clinical appearance (disseminated versus pulmonary disease), and pathogenesis (primary infection versus reactivation). These differences probably reflect differences in immunological and genetic control [10]. Although there is growing literature on the role of candidate genes from TLRs signaling pathway in adults, data from children are scarce [11]. Further studies of TB genetics in well-defined pediatric populations are urgently needed.

To date, there are no published data that describe the association between TLR8 SNPs and pediatric pulmonary TB. Whether a causal relationship exists between SNPs - 129 C/G (rs3764879) and Met1Val (rs3764880) of TLR8, a mediator of inflammatory process and infectious diseases, and pediatric pulmonary TB is unknown. The aim of this study was to determine whether these two SNPs of TLR8 were associated with pediatric pulmonary TB in Turkish population.

\section{Materials and methods}

\subsection{Study subjects}

This study was conducted in Istanbul at Sisli Etfal Training and Research Hospital and at Sureyyapasa Chest Diseases and Thoracic Surgery Teaching Hospi- tal, the two largest referral centers in Turkey. The study consisted of 124 immune-competent Turkish children with pulmonary TB in the study group and 150 healthy children in the control group. The control patients were matched with the TB patients by age, sex, and ethnicity. There were no significant differences between the groups for age and sex $(p>0.05)$.

Only patients who had definitive pulmonary TB diagnosed by positive culture results of mainly gastric and bronchial aspirates, and very occasionally sputum, were included in the study. Because polymorphisms may vary according to age, gender, ethnic group and disease, patients who had an additional disease such as acquired immune deficiency syndrome and/or malnutrition were excluded from the study.

The control group included 150 children who were sampled from the surgical outpatient department by random sampling; their gender, age, and region distribution information was matched with that of the TB patients. The controls were asymptomatic, had no history of TB and specific antimycobacterial treatment, had normal radiographic examination findings, negative PPD skin test, and/or no history of household contact with an index case. All of the controls were from the same ethnic and geographical origin, living in the same city as the TB cases.

A small questionnaire to collect the demographic information was given to the individuals. Only Turkish subjects were included in the study; therefore, the study sample consisted totally of Caucasians (Turkish), without any other ethnicities (African or Asian).

The study was approved by the local ethics committee of Sisli Etfal Training and Research Hospital and written informed consent was obtained from each child's parent. Blood samples were collected from the patients and controls in EDTA vials, and their clinical details were recorded. All the samples (n: 274) were stored at $4{ }^{\circ} \mathrm{C}$ before the analyses and were performed in accordance with the principles of The Declaration of Helsinki.

The -129 C/G(rs3764879)and Met1Val(rs3764880) polymorphisms of TLR8 (Gene access number: NM_ 138636.4; GeneID:51311) were investigated in the patients with pulmonary $\mathrm{TB}$ and in the controls in the Institute of Forensic Medicine, Ankara University.

\subsection{Genomic DNA preparation}

Genomic DNA was extracted from ethylenediaminetetraacetic acid (EDTA) anticoagulant peripheral whole blood samples using the QIAamp blood DNA 
mini-kit (Qiagen, Hilden, Germany) according to the method recommended by the manufacturer. Quantity and purity of DNAs were determined by spectrophotometry.

\subsection{Determination of $-129 \mathrm{C} / \mathrm{G}$ and Met $1 \mathrm{Val}$ polymorphisms of Toll-like receptor 8 by restriction fragment length polymorphism (RFLP) method}

TLR-8 gene $-129 \mathrm{C} / \mathrm{G}$ and Met 1 Val polymorphisms were genotyped by the method previously reported by Cheng et al. [12]. To screen for $-129 \mathrm{C} / \mathrm{G}$ and Met1 Val polymorphisms of TLR-8, 390 bp fragment was amplified by polymerase chain reaction (PCR) using the following primers: forward: 5'-GTG TGT GTC TGA TTT GGG TTG-3' and reverse 5'- TTT CTA GGC TCA CAC CAT TTG -3'.

Amplification was carried out on a Techne Tc 512 PCR System in a $50 \mu \mathrm{l}$ reaction mixture containing $200 \mu \mathrm{M}$ of dNTPs, $10 \mathrm{pmol}$ each of forward (F) and reverse (R) primers, 1 U Hot Star Taq DNA polymerase (Qiagen), 1 X PCR buffer (Qiagen), and $200 \mathrm{ng}$ genomic DNA. The PCR cycling conditions consisted of an initial denaturation step at $95^{\circ} \mathrm{C}$ for $5 \mathrm{~min}$, followed by 35 cycles as follows: $1 \mathrm{~min}$ at $94^{\circ} \mathrm{C}$ for denaturation, $1 \mathrm{~min}$ at $56^{\circ} \mathrm{C}$ for annealing, $45 \mathrm{~s}$ at $72^{\circ} \mathrm{C}$ for primer extension, and $10 \mathrm{~min}$ at $72^{\circ} \mathrm{C}$ for final extension step. Then the PCR product (390 bp) was digested with HpyCH4IV for $-129 \mathrm{C} / \mathrm{G}$ and NIaIII for Met1 Val and incubated at $37^{\circ} \mathrm{C}$ overnight. The PCR products were separated on a $3 \%$ agarose gel electrophoresis, visualized by ethidium bromide staining under an ultraviolet illuminator, and scanned and photographed using Syngene Monitoring System. Digestion of PCR product by HpyCH4IV (New England Biolabs, Hertfordshire, UK) yields $229 \mathrm{bp}$ and $161 \mathrm{bp}$ fragments for the presence of $\mathrm{C}$ allele; $390 \mathrm{bp}$ for the presence of $\mathrm{G}$ allele. Digestion of PCR product by NIaIII (New England Biolabs, Hertfordshire, UK) yields 156 bp, 137 bp and $97 \mathrm{bp}$ fragments for the presence of A (Methionine) allele; $253 \mathrm{bp}$ and $137 \mathrm{bp}$ fragments for the presence of $\mathrm{G}$ (Valine) allele.

\subsection{Statistical Analysis}

Statistical analyses were carried out using SPSS software, version 16.0 (SPSS, Chicago, IL, USA). Demographic and clinical data are expressed as means \pm SD or percentage. The Student's $t$-test was used for the comparison of numeric variables within groups.
Genotype distributions and allele frequencies between groups were compared using $2 \times 2$ contingency tables, Pearson $\chi^{2}$, Yates $\chi^{2}$, or Fisher's exact tests, as appropriate. Odds ratios (ORs) with $95 \%$ confidence intervals $(95 \% \mathrm{CI})$ were also calculated for these comparisons; $p<0.05$ was considered statistically significant. Allele and genotype frequencies among female controls were compared with values predicted by HardyWeinberg equilibrium using the Haldane exact test. Our sample size (power calculation) was determined using GraphPad PRISM software (GraphPad Software Inc., San Diego, CA, USA).

\section{Results}

Of the 124 patients, $62(50 \%)$ were female and $62(50 \%)$ were male. Their mean age was $105.58 \pm$ 56.55 months. The control group consisted of 78 (52\%) female subjects and $72(48 \%)$ male subjects with a mean age of $103.40 \pm 57.34$ months.

Using blood samples of children with pulmonary TB and the control group, we tested whether there is an association between pulmonary TB and $-129 \mathrm{G} / \mathrm{C}$ (rs3764879) and Met1 Val (rs3764880) polymorphisms in the TLR8 gene. The findings are summarized in Tables 1 and 2 .

The results indicated that the distributions of genotypes $\mathrm{GG}$ or $\mathrm{G} /(-), \mathrm{CG}$, and $\mathrm{CC}$ or $\mathrm{C} /(-)$ at rs3764879 of the pulmonary TB cases and healthy controls did not statistically significantly differ $(p>0.05)$ (Table 1). TLR8 is located on the Xp22.2 chromosome; we analyzed the males and females separately. There were no significant differences between the female pulmonary TB and female control groups for genotypes $\mathrm{GG}, \mathrm{CG}$, and CC; and alleles $\mathrm{G}$ and $\mathrm{C}$ frequencies at rs3764879 $(p>0.05)$. Similarly, in males, there were no significant differences between the male pulmonary TB and male control cases for genotype distribution frequencies at rs3764879 $(p>0.05)$.

There were no significant differences between the pulmonary TB and control groups in genotype distributions and allele frequencies at rs3764880 $(p>0.05)$ (Table 2). In the statistical analyses according to gender, we did not found any significant differences between the female pulmonary TB and female control groups for genotypes GG, AG and AA, or between alleles $\mathrm{G}$ and $\mathrm{A}$ frequencies at $\operatorname{rs} 3764880(p>0.05)$. We found a strong association with genotype $\mathrm{A} /(-)$ at rs3764880 with susceptibility to pulmonary TB in males (OR 2.87, 95\%CI 1.38-5.98, $p=0.007$ ). In 
Table 1

Genotype and allele distributions at TLR8 - 129 C/G (rs3764879) in pediatric pulmonary TB cases and controls and genotyping according to sex

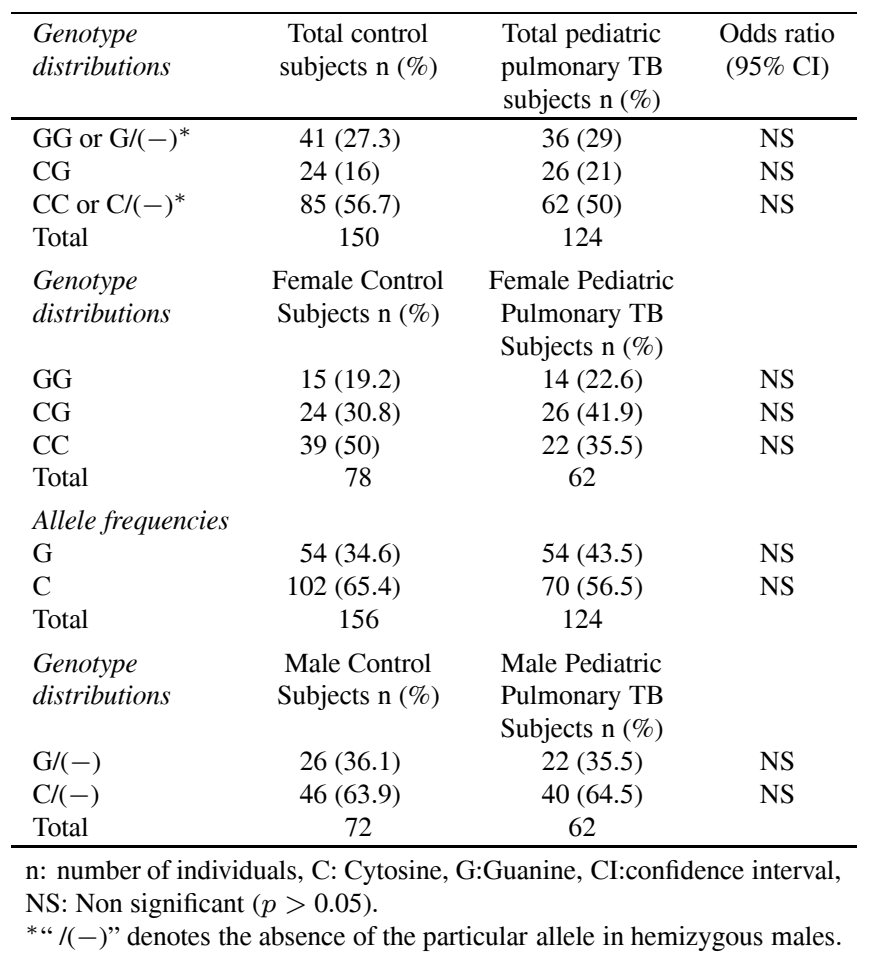

addition, $\mathrm{G} /(-)$ genotype frequency was significantly lower $(28.8 \%$ vs. $50 \%$, OR 0.43 , 95\%CI $0.16-0.72$, $p=0.007$ ) in the male patients with pulmonary TB when compared with the male healthy controls.

\section{Discussion}

TLRs play an important role in the innate immune recognition of invading microorganisms, initiating adaptive immune responses. Some individuals may not respond properly to TLR ligands because of SNPs within the TLR genes, causing defects in intracellular signal transductions and resulting in altered susceptibility to infectious diseases [4]. The most recently described TLRs to be implicated in responding to viral stimulation are TLR7 and TLR8, which share a high degree of structural similarity [5]. TLR8 is unusual, as it seems to be redundant in mouse but plays a critical role in humans. It is particularly fortunate that two of the novel TLRs (TLR7 and TLR8) reside on the X chromosome. As such, phenotypically detectable mutations should be recoverable in males, and in some females, depending upon the extent of X-inactivation to which the normal allele is subject [13]. A number of previ- ous studies have explored the occurrence of SNPs of TLR8 in various diseases and healthy populations. Triantafilou et al. reported that human cardiac inflammatory responses triggered by coxsackie B viruses are mainly TLR8-dependent [14]. It has been shown that TLR8 expression may be involved in the immune response to enterovirus $(\mathrm{EV})$ replication in EV-associated dilated cardiomyopathy (DCM). In addition, TLR8 may provide important prognostic information in patients with EV-associated DCM [15,16]. Cheng et al. investigated whether TLR8 Met1Val and TLR8 - 129G >C SNPs were asoosiated with coronary artery disease (CAD) in Chinese population [12]. They found no significant differences between CAD cases and controls in genotypic or allelic frequencies of these two SNPs. To our knowledge, this is the first study analyzing the association of SNPs rs3764879 and rs3764880 of TLR8 with pediatric pulmonary TB.

Pediatric TB is clinically different from adult TB, and investigation of the effects of susceptible genes on pediatric TB will provide additional information about the molecular genetic mechanisms involved in pediatric TB development and also aid in the establishment of moreefficient ways to prevent TB spread. Although there is growing literature on the role of SNPs of genes encod- 
Table 2

Genotype and allele distribution at TLR8 Met1Val (rs3764880) in pediatric pulmonary TB cases and controls and genotyping according to sex

\begin{tabular}{|c|c|c|c|}
\hline Genotype distributions & $\begin{array}{c}\text { Total control } \\
\text { subjects } \mathrm{n}(\%)\end{array}$ & $\begin{array}{l}\text { Total pediatric } \\
\text { pulmonary TB } \\
\text { subjects } \mathrm{n}(\%)\end{array}$ & Odds ratio $(95 \% \mathrm{CI})$ \\
\hline $\begin{array}{l}\text { GG or } \mathrm{G} /(-)^{*} \\
\mathrm{AG} \\
\text { AA or } \mathrm{A} /(-)^{*} \\
\text { Total }\end{array}$ & $\begin{array}{l}51(34) \\
26(17.3) \\
73(48.7) \\
\quad 150\end{array}$ & $\begin{array}{l}29(23.4) \\
26(21) \\
69(55.6) \\
\quad 124\end{array}$ & $\begin{array}{l}\text { NS } \\
\text { NS } \\
\text { NS }\end{array}$ \\
\hline $\begin{array}{l}\text { Genotype } \\
\text { distributions }\end{array}$ & $\begin{array}{l}\text { Female Control } \\
\text { Subjects n (\%) }\end{array}$ & $\begin{array}{c}\text { Female Pediatric } \\
\text { Pulmonary TB } \\
\text { Subjects n }(\%)\end{array}$ & \\
\hline $\begin{array}{l}\text { GG } \\
\text { AG } \\
\text { AA } \\
\text { Total }\end{array}$ & $\begin{array}{c}15(19.2) \\
26(33.3) \\
37(47.5) \\
78\end{array}$ & $\begin{array}{l}13(21) \\
26(41.9) \\
23(37.1) \\
62\end{array}$ & $\begin{array}{l}\text { NS } \\
\text { NS } \\
\text { NS }\end{array}$ \\
\hline $\begin{array}{l}\text { Allele frequencies } \\
\mathrm{G} \\
\mathrm{A} \\
\text { Total }\end{array}$ & $\begin{array}{c}56(35.9) \\
100(64.1) \\
156\end{array}$ & $\begin{array}{c}52(41.9) \\
72(58.1) \\
124\end{array}$ & $\begin{array}{l}\text { NS } \\
\text { NS }\end{array}$ \\
\hline $\begin{array}{l}\text { Genotype } \\
\text { distributions }\end{array}$ & $\begin{array}{l}\text { Male Control } \\
\text { Subjects n }(\%)\end{array}$ & $\begin{array}{l}\text { Male Pediatric } \\
\text { Pulmonary TB } \\
\text { Subjects n }(\%)\end{array}$ & \\
\hline $\begin{array}{l}\mathrm{G} /(-) \\
\mathrm{A} /(-) \\
\text { Total }\end{array}$ & $\begin{array}{c}36(50) \\
36(50) \\
72\end{array}$ & $\begin{array}{c}16(28.8) \\
46(74.2) \\
62\end{array}$ & $\begin{array}{l}0.43(0.16-0.72)^{* *} \\
2.87(1.38-5.98)^{* *}\end{array}$ \\
\hline
\end{tabular}

ing TLRs in adults, data from children are scarce. This is surprising given the marked differences in TB pathophysiology between adults and children, which could also reflect differences in genetic factors. TLR 8 is located on chromosome $\mathrm{X}$, which suggests that any allele conferring susceptibility to disease may well have a higher impact among males who carry only one copy of the gene. Davila et al. found that four polymorphisms (rs3764879, rs3788935, rs3761624, rs3764880) in the TLR8 gene showed evidence of association with TB susceptibility in males in adults [9]. Their results provide for the first time, of a role for the TLR8 gene in susceptibility to pulmonary TB across different populations. We found evidence that TLR8 Met1 Val polymorphism is associated with susceptibility to pulmonary TB among male children, similar to the study findings of Davila et al. Our study is the first in the literature to find a 2.87-fold tendency in a SNPs genotype of a gene (A) for pulmonary TB in male children. In addition, genotype $\mathrm{G} /(-)$ of rs 3764880 was associated with protection from TB in males with a 0.43 -fold tendency. We did not detect any associations with TLR8 - 129 C/G polymorphism for TB susceptibility in children, whereas Davila et al. found a strong allelic association with minor allele $\mathrm{C}$ of the putatively functional polymor- phism rs3764879, with susceptibility to pulmonary TB in males.

Ethnic differences in TLR polymorphisms may in part reflect the ethnic diversity of host viral susceptibility. For this reason, most of the studies on TLR polymorphisms have been deliberately ethnically matched to avoid genetic diversity. Davila et al. found that around $30 \%$ of the Indonesian male subjects carried the A allele (Met) associated with risk for TB, whereas this same allele was present in $78 \%$ of Russian patients [9]. Our data indicate that $34.3 \%$ of the Turkish male children with pulmonary TB had the A allele associated with risk for TB, which is similar to Indonesion population. The Met1Val polymorphism of TLR8 was observed more than $16 \%$ among the healthy Chinese adult population by Cheng et al. [12]. We identified the same SNP in $26.6 \%$ of healthy Turkish children in our study.

TB continues to cause an unacceptably high toll of disease and death among children worldwide. Whereas intense scientific and clinical research efforts into novel diagnostic, therapeutic, genetic and preventive interventions have focused on TB in adults, childhood TB has been relatively neglected. However, children are particularly vulnerable to severe disease and death following infections, and those with latent infection 
become the reservoir for future transmission following disease reactivation in adulthood, fuelling future epidemics.

In conclusion, our results provide evidence, for the first time, of a role for the TLR8 gene in susceptibility to childhood pulmonary TB. Advances in our understanding of childhood TB genetics would provide insights and opportunities to enhance efforts to control this disease.

\section{References}

[1] S. Swaminathan and B. Rekha, Pediatric Tuberculosis: Global Overview and Challenges, Clinical Infectious Diseases $\mathbf{5 0}$ (2010), S184-S194.

[2] R. Medzhitov and C.A. Jr. Janeway, Innate immunity: the virtues of a nonclonal system of recognition, Cell 91 (1997), 295-298.

[3] R.R. Schumann, Host cell-pathogen interface: molecular mechanisms and genetics, Vaccine 22 (2004), S21-S24.

[4] N.W. Schröder and R.R. Schumann, Single nucleotide polymorphisms of Toll-like receptors and susceptibility to infectious disease, Lancet Infectious Diseases 5 (2005), 156-164.

[5] D.Y. Oh, S. Taube, O. Hamouda, C. Kücherer, G. Poggensee, H. Jessen, J.K. Eckert, K. Neumann, A. Storek, M. Pouliot, P. Borgeat, N. Oh, E. Schreier, A. Pruss, K. Hattermann and R.R. Schumann, A functional toll-like receptor 8 variant is associated with HIV disease restriction, Journal of Infectious Diseases 198 (2008), 701-709.

[6] B. Beutler, Z. Jiang, P. Georgel, K. Crozat, B. Croker, S. Rutschmann, X. Du and K. Hoebe, Genetic analysis of host resistance: Toll-like receptor signaling and immunity at large, Annual Review Of Immunology 24 (2006), 353-389.

[7] S.S. Diebold, T. Kaisho, H. Hemmi, S. Akira and C. Reis e Sousa, Innate antiviral responses by means of TLR7-mediated recognition of single-stranded RNA, Science 303 (2004),
$1529-1531$.

[8] F. Heil, H. Hemmi, H. Hochrein, F. Ampenberger, C. Kirschning, S. Akira, G. Lipford, H. Wagner and S. Bauer, Speciesspecific recognition of single-stranded RNA via toll-like receptor 7 and 8, Science 303 (2004), 1526-1529.

[9] S. Davila, M.L. Hibberd, R. Hari Dass, H.E. Wong, E. Sahiratmadja, C. Bonnard, B. Alisjahbana, J.S. Szeszko, Y. Balabanova, F. Drobniewski, R. van Crevel, E. van de Vosse, S. Nejentsev, T.H. Ottenhoff and M. Seielstad, Genetic association and expression studies indicate a role of toll-like receptor 8 in pulmonary tuberculosis, PLoS Genetics 4 (2008), e1000218.

[10] A. Alcais, C. Fieschi, L. Abel and J.L. Casanova, Tuberculosis in children and adults: two distinct genetic diseases, Journal of Experimental Medicine 202 (2005), 1617-1621.

[11] S.M. Newton, A.J. Brent, S. Anderson, E. Whittaker and B. Kampmann, Paediatric tuberculosis, Lancet Infectious Diseases 8 (2008), 498-510.

[12] P.L. Cheng, H.L. Eng, M.H. Chou, H.L. You and T.M. Lin, Genetic polymorphisms of viral infection-associated Toll-like receptors in Chinese population, Translational Research $\mathbf{1 5 0}$ (2007), 311-318.

[13] X.Du, A. Poltorak, Y. Wei and B. Beutler, Three novel mammalian toll-like receptors: gene structure, expression, and evolution, European Cytokine Network 11 (2000), 362-371.

[14] K. Triantafilou, G. Orthopoulos, E. Vakakis, M.A. Ahmed, D.T. Golenbock, P.M. Lepper and M. Triantafilou, Human cardiac inflammatory responses triggered by Coxsackie B viruses are mainly Toll-like receptor (TLR) 8-dependent, Cellular Microbiology 7 (2005), 1117-1126.

[15] S. Fujioka, Y. Kitaura, H. Deguchi, A. Shimizu, T. Isomura, H. Suma and H.N. Sabah, Evidence of viral infection in the myocardium of American and Japanese patients with idiopathic dilated cardiomyopathy, American Journal of Cardiology 94 (2004), 602-605.

[16] M. Satoh, T. Akatsu, Y. Ishikawa, Y. Minami, Y. Takahashi and M. Nakamura, Association between toll-like receptor 8 expression and adverse clinical outcomes in patients with enterovirus-associated dilated cardiomyopathy, American Heart Journal 154 (2007), 581-588. 


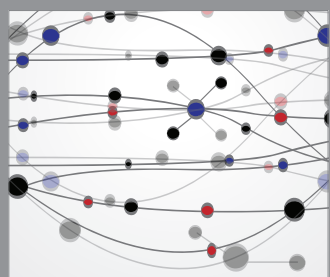

The Scientific World Journal
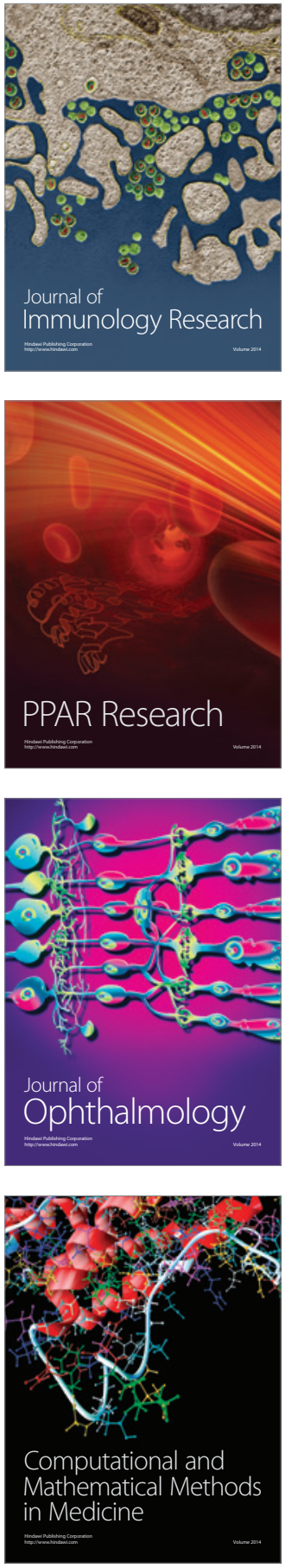

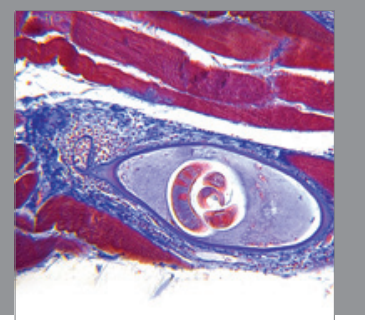

Gastroenterology

Research and Practice
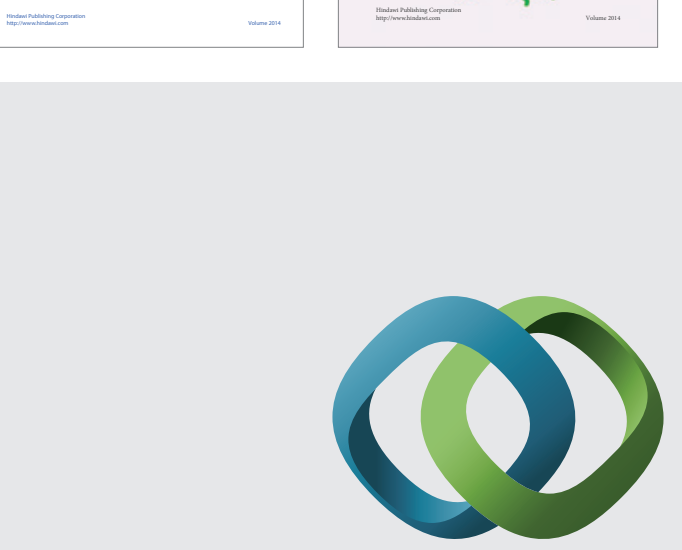

\section{Hindawi}

Submit your manuscripts at

http://www.hindawi.com
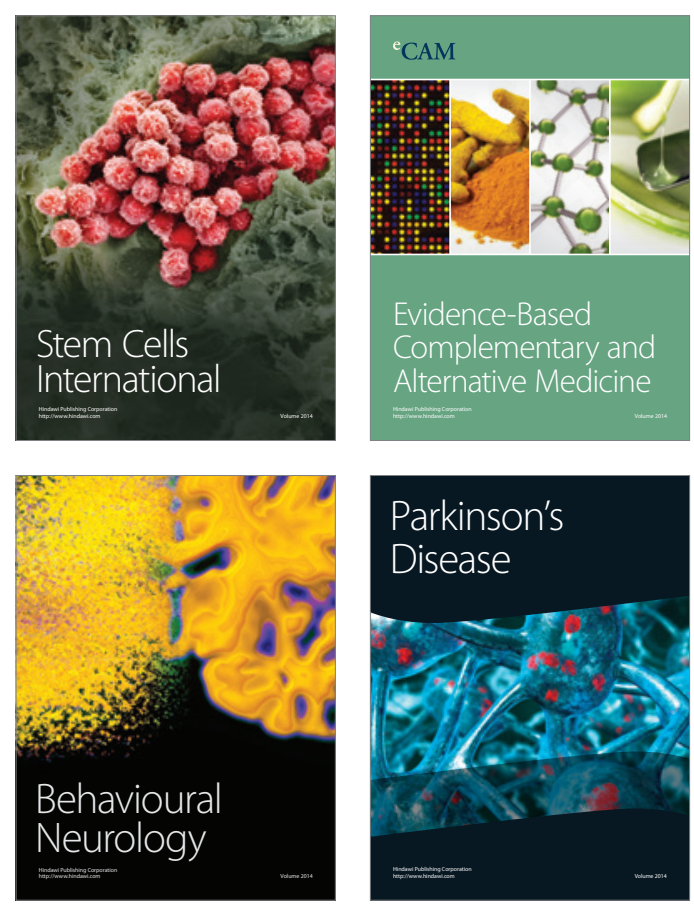

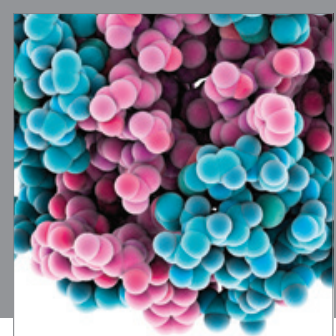

Journal of
Diabetes Research

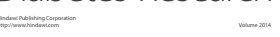

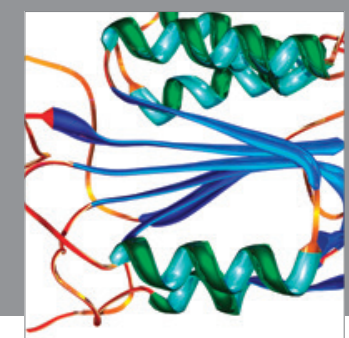

Disease Markers
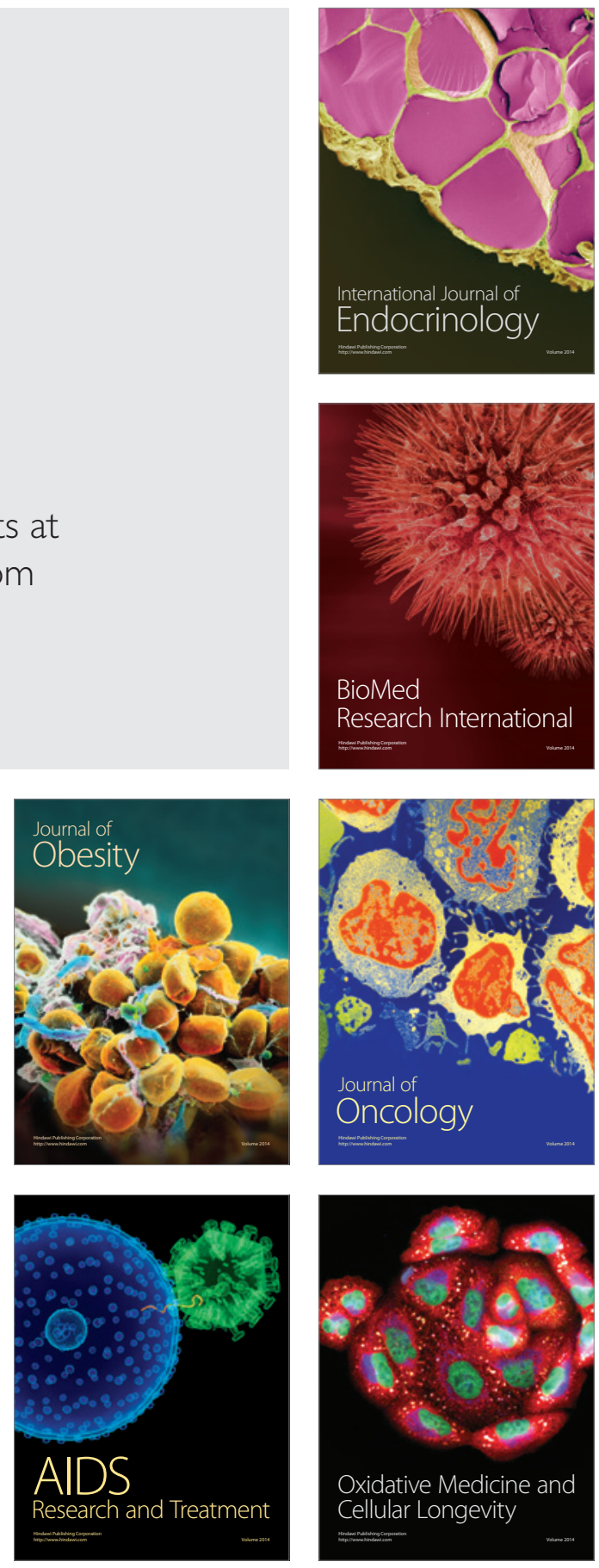